\title{
The Avian Ethics of Facades: Considering Wildlife Constituencies in Architectural Design
}

\author{
SCOTT MURRAY \\ University of Illinois at Urbana-Champaign
}

Collisions with building facades result in the deaths of hundreds of millions of birds annually in the United States. The ways in which building facades are designed can have direct impact on this tragic number, either positively or negatively. This paper argues that our conception of architectural ethics must be expanded to address buildings' impact on wildlife constituencies, taking the building envelope and its effects on birds as a primary test case. The effective integration of bird-safe approaches to facade design require the architect to possess, in equal measures, ecological and technological literacy. An understanding of the migration patterns and other behaviors of birds must be paired with detailed knowledge about glass properties and fabrication possibilities. Ultimately, as the paper explains, this approach requires us to form an expanded concept of subjectivity and site in architecture.

\section{INTRODUCTION}

During a storm on the night of May 3, 2017, a total of 395 migratory birds died upon impact with a single high-rise building in Galveston, Texas. Just three stunned though still-alive birds were found among the dead (which included 25 different species) at the base of the 23-story American National Insurance tower. Officials believe that the birds-which were following their natural migratory patterns from South and Central America to North America-became disoriented by the tower's lights and slammed into its façade, perhaps propelled by strong winds during the storm. ${ }^{1}$ During their annual spring migration season, hundreds of thousands of birds fly through the region surrounding Galveston. ${ }^{2}$ The conservation manager for the Houston Audobon Society said, "The Texas coast is the first land these migrants encounter after crossing the Gulf of Mexico, [and] right away they're looking for habitat. ${ }^{\prime 3}$ Due to a combination of interior office lighting and exterior floodlights, the birds were apparently unable to sense the tower's large, transparent-glass windows as a solid barrier and flew directly into them, possibly seeking clear passage or a place to rest.

Directly stated, the deaths of these 395 birds-accidental and unintended as they may be-represent the destruction of wildlife by architecture and, more specifically, by building facades. What ethical responsibilities do architects have toward such non-human constituencies? How can architecture promote a definition of sustainability that is broad enough to include sustaining and protecting wildlife populations? This paper argues that such questions require architects to develop a broader and more complex architectural understanding of subjectivity and site.

\section{CONTEXT}

Although tragic, the recent Galveston incident is just one small and unfortunately commonplace example of a larger problem. Ornithologists estimate that collisions with buildings-and particularly collisions with windows-are responsible for between 365 million and nearly 1 billion bird deaths annually in the United States. ${ }^{4}$ This count dwarfs the number of annual bird deaths from other human-related factors such as hunting (120 million), vehicular collisions (60 million), and wind turbines $(400,000) .{ }^{5}$ One group of researchers from the Smithsonian Conservation Biology Institute has written that "buildings are a globally ubiquitous obstacle to avian flight" and collisions with them present "a major anthropogenic threat to North American birds." Audobon Minnesota calls it "a threat of sufficient magnitude to affect the viability of bird populations, leading to local, regional, and national declines."7 Another group of ornithologists has predicted that "the hazard that clear and reflective sheet glass poses to birds is expected to increase as urban areas increase" and as new buildings are constructed in avian breeding areas and across migratory routes worldwide. ${ }^{8}$

Why are bird collisions with building facades so numerous and common? The nearly ubiquitous presence of glass in all building facades is a major contributor to this phenomenon. Birds and humans have fundamentally different relationships and responses to glass facades. Whereas to humans the benefits of fenestration in a building envelope are obvious (natural lighting, ventilation, a visual connection to the outdoors) and only slightly tempered by disadvantages (poor thermal performance, possible safety issues), to birds a large pane of glass presents only a hidden and potentially lethal obstacle. To them it is void of usefulness and full of danger. Vertical glass surfaces, whether transparent or reflective, create a visual illusion for birds. During daylight hours, when most collisions occur as birds are out feeding, they commonly see reflections of the landscape, trees, or clouds on the glass surface which registers to them as a clear passage or a spatial continuation of the exterior environment. ${ }^{9}$ At night, electrical lighting of buildings (both inside and outside) acts as a beacon, especially for night-migrating species, attracting birds looking for a resting place, especially if any interior plants or landscaping are illuminated behind the glass. Such disorienting and confusing signals caused by nighttime lighting are exacerbated when combined with fog or other inclement weather conditions, as was the case in Galveston. 


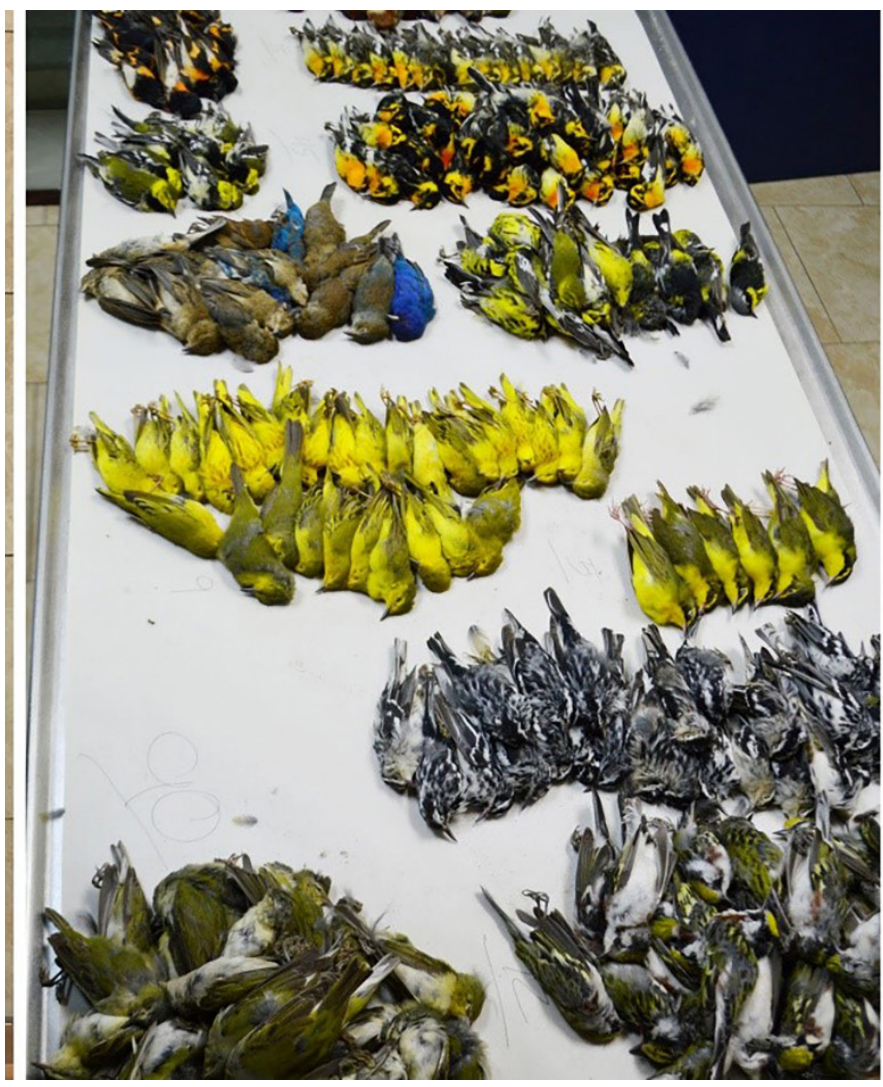

Figure 1: Dead birds, grouped by species, found at the base of the American National Insurance Tower in Galveston, Texas, on the morning of May 4, 2017. Photo by Josh Henderson, Galveston Police Department, Animal Services Unit.

Given these parameters, the strategies for mitigating bird strikes involve action in two realms: (1) building design and (2) building operations. In building design, architects must be aware of the properties of glass which make it dangerous to birds and must understand the potential solutions. The orientation and placement of buildings and landscape elements, the size and proportion of windows, the spacing of mullions and/or shading devices, the types of glass, and the inclusion of patterns or specialized coatings on glass all present opportunities for reducing bird strikes. In building operations, the control or limitation of nighttime illumination (especially during periods of migration) and the deployment of interior window coverings (shades, blinds, or curtains) have been shown to effectively reduce the incidence of bird collisions. ${ }^{10}$ While the ethical imperative to design bird-safe buildings largely depends upon architects' willingness to engage these issues, there increasingly are governmental mandates or incentives to do so. Some municipalities have begun establishing codes and standards addressing this topic: examples include the City of Chicago's Bird Agenda, established in 2006, and the San Francisco Planning Commission's Standards for Bird Safe Buildings, passed in 2011.

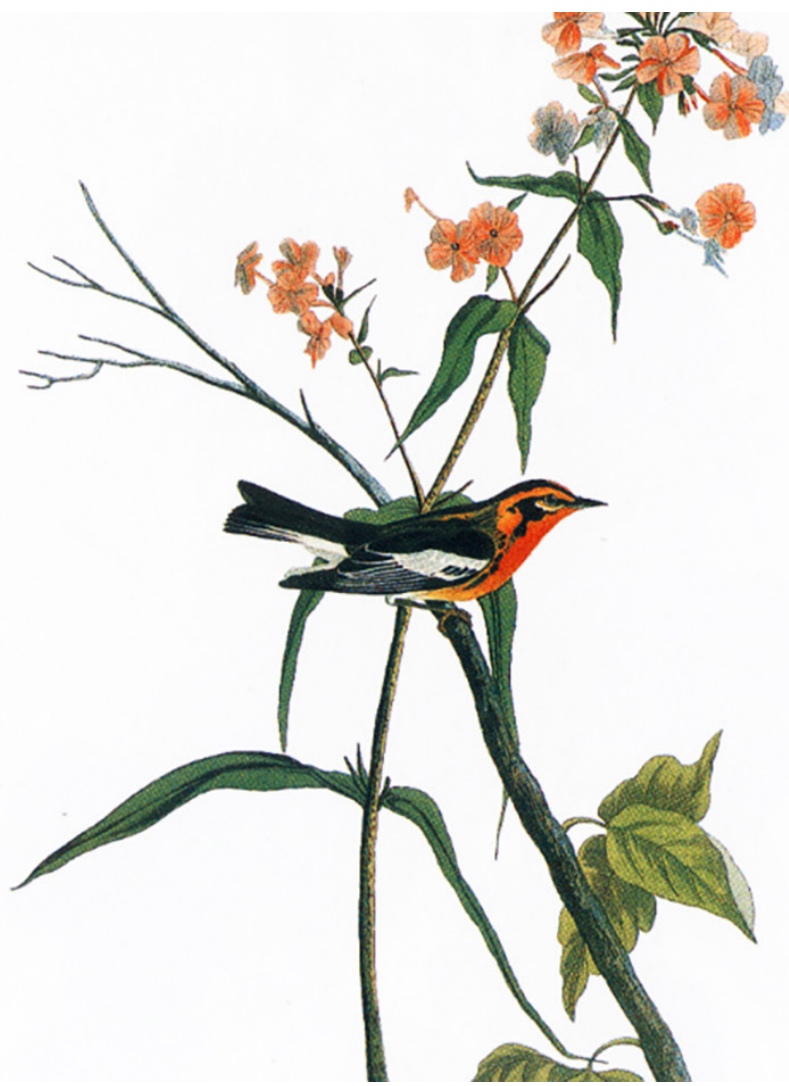

Figure 2: Blackburnian Warbler (Setophaga fusca), painting by John James Audobon. 60 Blackburnian warblers were among the 395 birds found dead in Galveston.

\section{EXPANDING CONCEPTS OF SUBJECTIVITY AND SITE}

In general practice, constituency in architecture is typically defined as, primarily, a building's users or occupants (the people among whom the building's impact is most directly experienced on a daily basis) and, secondarily, as the broader human community within which a building exists (neighbors, visitors, other residents of the city). This is a logical, practical, and historically dominant formulation of subjectivity in architecture. However, an ecologically ethical approach requires a broadening of this concept. The potential impacts of architecture clearly extend beyond its human occupants to landscapes, fauna, and climate. Architecture's inevitable and various impacts on wildlife may be beneficial (in the case of habitat creation by green roofs, for example) or, on the other hand, detrimental (in the case of bird-to-glass casualties). When thinking about the constituencies of the buildings and places they design, architects must embrace this more complex definition of subjectivity if they intend to call their work sustainable in any comprehensive sense.

Elaine Scarry has written that the act of making is always full of ethical content, and that we expect artifacts to "make sentient" the external world-that is, an artifact should "recognize" the existence of its human user and respond with specificity to that person's needs and desires (like the way 

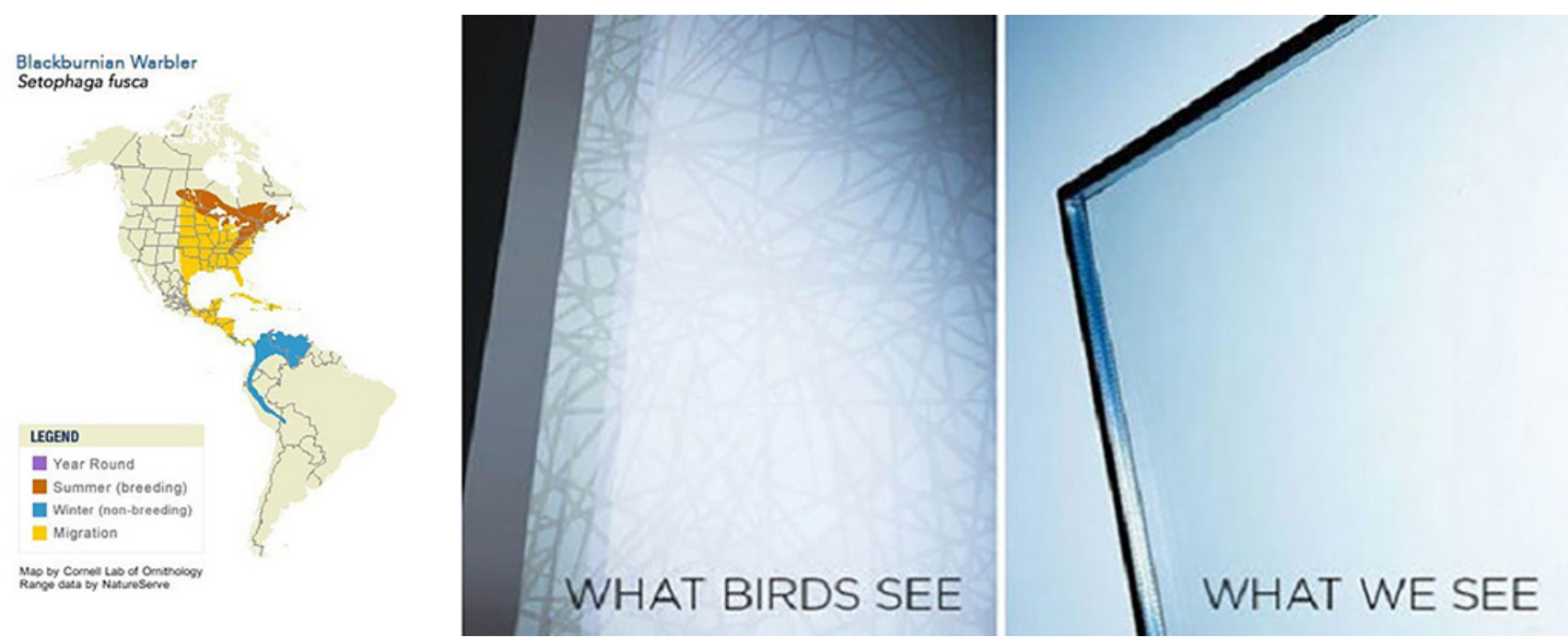

Figure 3 (left): Migration map for the Blackburnian Warbler (Cornell Lab of Ornithology). Figure 4 (right): Ornilux Bird Protection Glass utilizes a patterned ultraviolet-reflective coating that is visible to birds but nearly invisible to humans.

a well-designed chair recognizes ergonomics).11 She writes that designed and constructed objects "must internalize within their design an active 'awareness' of human beings" and that an object must also be "self-aware," meaning that its design must anticipate how it might be used or misused.12 While Scarry's theory focuses on human/object relations, this concept can be readily applied to the relationship between architecture and wildlife; that is, architecture should also "recognize" the existence of non-human constituents and, at a minimum, do no harm. This means that a building façade must be "aware" of the natural phenomena of bird behavior, migratory flight patterns, and the dangers of bird impacts with glass. Such an awareness must be designed into the building envelope by the architect.

This approach to designing "externally sentient" artifacts must also necessarily involve rethinking the concept of site in architecture. One might consider the site for a tower in Galveston, Texas, to constitute the buildable plot of land on which it sits. In a slightly broader and more inclusive sense, one might consider the immediate neighborhood or district as the site for such a building, including the surrounding structures with which it will form the urban fabric. However, a much broader and less myopic conception of site comes into play once wildlife is accepted as an important constituency for the built environment. An understanding of the migratory paths of birds, for instance, would require one to see a site in Galveston as directly linked to places as far away as Bolivia to the south and Saskatchewan to the north.

Consider one of the species of birds killed in the Galveston incident: the Blackburnian Warbler (Figs. 1 and 2). According to the Audobon Field Guide, this colorful bird, with its orange and black plumage ("a fiery gem of the treetops"), winters in the Andes of South America and then migrates north across the Gulf of Mexico-often passing through Galveston-to its summer breeding grounds in the northern U.S. and Canada, then reversing this voyage again each fall (Fig. 3). ${ }^{13}$ Thus, the Blackburnian Warbler's habitat (like most migrating birds) encompasses a vast geography across multiple continents, including rural and agricultural landscapes but also cities like Galveston, Chicago, Atlanta, and New York. Audobon reports that climate change over the next 60 years will likely cause geographic shifts in this species' migration patterns, adding further complexity. ${ }^{14}$ In its conservation status report for the Blackburnian Warbler, Audobon notes that it "may be especially vulnerable to loss of wintering habitat, with cutting of forest at mid-levels in mountains in the tropics." ${ }^{15}$ In addition to the perils of habitat destruction, the Balckburnian Warbler faces the threat of building collision mortality due to the design of buildings sited within its vast migration territory, as seen in the specific example of the Galveston tower in 2017. Although the warbler may be only a temporary resident of a city like Galveston, an ecologically-ethical approach to designing a building there must recognize the vastness of the "site" and its connection to a larger region.

In his book Postmodern Ethics, Zygmunt Bauman notes that too often the individual imagination cannot embrace the farthest, large-scale ramifications of individual actions, "however closely they may intertwine with what we do, or abstain from doing."16 The effects of a building upon wildlife constituencies-particularly those who only temporarily migrate through a site-may seem like a relatively distant or even insignificant issue to an architect. But in Bauman's view, an ethical stance requires one to "grow" one's understanding of our actions' sphere of influence. When it comes to buildingenvelope design, an ethical approach will require the architect to integrate thinking about bird impacts along with the typical issues of materiality, energy performance, fabrication, and aesthetics. It is important to note that this represents an expansion of subjectivity in architecture, not a restriction or 
replacement; in other words, architects are ethically obliged to consider the avian ramifications of their designs not to the exclusion of human concerns but in addition to them. Architectural design is always a "messy" endeavor due to the comprehensive range of issues that must be engaged: social, economic, technological, legal, and here, with respect to wildlife and habitat, ecological.

\section{DESIGN AND TECHNOLOGY}

In order to effectively integrate a bird-safe approach to building-envelope design, the architect must possess, in equal measures, ecological and technological literacy. An understanding of wildlife, habitat, and climate must inform decisions relating to material choice, detailing, and fabrication. Such decisions occur at the macro level (siting, orientation, and massing of the building relative to natural features, migration routes, and vegetation) and at the micro level (material specifications, window or curtain wall configurations, and details). Given that glass presents the most serious threat to birds, architects must understand the full range of fenestration compositions and products which may reduce that threat.

Several advocacy organization, glass manufacturers, and scientists have in recent years conducted research and published guidelines intended to demystify the façade-design parameters related to birds. Among the most comprehensive guides is the American Bird Conservancy's Bird-Friendly Building Design guidebook, which proposes that "constructing birdfriendly buildings and eliminating the worst existing threats requires imaginative design and recognition that not only do birds have a right to exist, but their continued existence is a value to humanity." ${ }^{17}$ The primary objective regarding glass is to reduce its illusory visual effects that cause birds to perceive it as open space due to reflections or transparency. This can be achieved through the addition of external devices which signal the presence of a barrier to birds: these may include grates, grilles, netting, or shutters positioned on the exterior side of glass. It is also possible that architectural elements serving another purpose altogether, such as external shading devices like louvers, fins or perforated panels, can simultaneously serve as bird-strike deterrents. Aside from such auxiliary devices, there are other effective techniques which can be incorporated directly into or onto the glass product itself. Patterns applied to the surface of glass-using silk-screened ceramic frit or acid-etching, for instance-can prevent bird collisions as well. This technique can likewise serve multiple purposes: such patterns are often used to reduce solar heat gain and/or for visual privacy. Printed patterns break up reflections and are perceptible to birds as an obstacle; research has shown that patterns covering only $5 \%$ of the total glass surface can reduce bird collisions by up to $90 \%$ under test conditions. ${ }^{18}$ Guidelines for the geometry and spacing of such patterns generally follow the " 2 x 4 rule," which states that birds generally will not attempt to fly through a space that is 2 inches or less in height and 4 inches or less in width. ${ }^{19}$ Although under controlled conditions research has suggested that glass panes angled at 20 to 40 degrees may result in less bird mortality compared to vertical panes, real-world applications have proven that angled glass provides no increased efficacy due to the fact that birds approach facades from multiple angles; therefore patterned glass remains the most viable solution.

Newly developed products offer an option for patterns on glass that are visible to birds but virtually invisible to humans. Because most birds can see light in the ultraviolet (UV) spectrum, while humans cannot, manufacturers have developed specialized UV-reflective coatings that can be applied to glass (similarly to ceramic frit) that will deter birds but remain nearly transparent to humans (Fig. 4). ${ }^{20}$ For retrofit applications in existing buildings, there are a number of commerciallyavailable adhesive films and decals that contain patterns proven to deter birds. ${ }^{21}$ Examples of integrating bird-safe design strategies for facades can be found in several recent projects, including Studio Gang's Ford Calumet Environment Center, SOM's US Census Bureau Headquarters, and Ennead Architects' Bridge for Laboratory Sciences at Vassar College.

\section{CONCLUSION}

In recent years, certain quarters of architectural discourse have embraced a biophilic design ethos that emphasizes a connection between design and the beneficial experience of nature in the built environment. ${ }^{22}$ This concept derives from the biologist and naturalist Edward O. Wilson's 1984 book, Biophilia, which argues that human beings' natural affinity for life binds us to all other forms of life on earth. ${ }^{23}$ In his 2002 book The Nature of Design: Ecology, Culture, and Human Intention, the environmentalist David Orr writes about this affinity:

"The growing evidence supporting the biophilia hypothesis suggests that we fit better in environments that have more, not less nature. We do better with sunlight, contact with animals, and in settings that include trees, flowers, flowing water, birds, and natural processes than in their absence. We are sensuous creatures who develop emotional attachments to particular landscapes. The implication is that we need to create communities and places that resonate with our evolutionary past and for which we have deep affection." ${ }^{24}$

For architects, this deep connection between humans and the greater natural world should impact the priorities, processes, and products of architectural design. It requires that we expand our thinking about site-about the physical and temporal contexts of our projects - to include natural habitat and territorial migration. It further demands an expanded concept of subjectivity in architecture, to encompass not only human constituents but also wildlife, such as the Blackburnian Warbler and the other 24 bird species killed at the tower in Galveston, Texas, in addition to other forms of wildlife whose natural habitat is impacted by increased development 
worldwide. If architects truly aim (as they often claim) to contribute to a more sustainable future, these ecologically ethical obligations toward wildlife must take their place among other important $21^{\text {st }}$-century issues like social equity, energy performance, and technological advancement.

\section{ENDNOTES}

1 Karin Brulliard, "One tall building. One dark and stormy night. 395 dead birds." The Washington Post, 15 May 2017. https://www.washingtonpost.com/news/ animalia/wp/2017/05/10/one-tall-building-one-dark-and-stormy-night395-dead-birds/?utm_term $=.0 \mathrm{~d} 82840996 \mathrm{~b} 4$

2 Meghan Bartels, "Nearly 400 Migratory Birds Were Kiled by One Texas Building in a Single Night." Audobon News, 5 May 2017. http://www.audubon.org/ news/nearly-400-migratory-birds-were-killed-one-texas-building-single-night.

3 As quoted in Brulliard, "One tall building."

4 Scott R. Loss, Tom Will, Sara S. Loss, and Peter P, Marra, "Bird-building collisions in the United States: Estimates of annual mortality and species vulnerablility," The Condor: Ornithological Applications 116 (2014), 8. They report that the number of bird deaths by building-collision are second only to those killed by feral and free-ranging pet cats, estimated to be about four times as many deaths per year.

5 Daniel Klem, et al., "Architectural and Landscape Risk Factors Associated with Bird-Glass Collisions in an Urban Environment," The Wilson Journal of Ornithology 121:1 (2009), 126

6 Ibid., 9.

7 Joanna Eckles, Project Director, "Bird-Safe Building Guidelines,"

Audobon Minnesota (May 2010), 6. http://mn.audubon.org/sites/g/files/ amh601/f/05-05-10_bird-safe-building-guidelines.pdf

8 Klem, "Architectural and Landscape Risk Factors," 133.

9 See "Reducing Bird Collisions with Buildings and Building Glass Best Practices," U.S. Fish and Wildlife Service, Division of Migratory Bird Management, January 2016 (Updated July 2016).

10 Ibid., 8

11 Elaine Scarry, The Body in Pain: The Making and Unmaking of the World (New York: Oxford, 1985), 281

12 Ibid., 302-303.

13 "Blackburnian Warbler," Audobon Guide to North American Birds. http://www. audubon.org/field-guide/bird/blackburnian-warbler

14 Ibid.

15 Ibid.

16 Zygmunt Bauman, Postmodern Ethics (Oxford: Blackwell, 1993), 218.

17 Bird-Friendly Building Design, American Bird Conservancy (ABC) with the NYC Audobon Society. https://abcbirds.org/wp-content/uploads/2015/04/Birdfriendly_Building_Guide_WEB.pdf

18 Ibid., 17

19 Ibid., 17.

20 See, for example, Ornilux Bird Protection Glass. http://ornilux.com/

21 See, for example, CollidEscape products. http://www.collidescape.org/

22 See Stephen Kellert, Judith Heerwagen, and Martin Mador, eds., Biophilic Design: The Theory, Science, and Practice of Bringing Buildings to Life (Hoboken: Wiley, 2008), vii.

23 Edward O. Wilson, Biophilia (Cambridge, Mass.: Harvard, 1984).

24 David Orr, The Nature of Design: Ecology, Culture, and Human Intention (Oxford: Oxford University Press, 2002), 25-26. 